\title{
National Social Attitudes and Political Appeals in the Process of Rising of Competitive Sports in China
}

\author{
Shu Shengfang ${ }^{1, *}$, Wang Mina ${ }^{2}$ \\ ${ }^{1}$ Physical Education \& Training Institute, Shanghai University of Sport, China \\ ${ }^{2}$ Weihai Translation Center, China
}

Copyright $(2016$ by authors, all rights reserved. Authors agree that this article remains permanently open access under the terms of the Creative Commons Attribution License 4.0 International License

\begin{abstract}
There are three developing phases of Chinese competitive sports in term of national social attitudes and political appeals in the past sixty years. In the first 30 years, reluctance to show weakness or suffering disgrace reflected social attitudes, while the political appeals were to promote the national prestige, to wash off the shame of "Sick Man of East Asia" and to gain the international dignity in the worldwide playing fields; In the latter 30 years, the social attitudes appeared as the rising of nationalist sentiment, while the political appeals were to "bring about a great rejuvenation of the Chinese nation with the Olympic success". Since the Beijing Olympics, the national social attitude diversified while the Gold Medal became not as important as before. And the political appeals were the pursuit of "Harmonious World".
\end{abstract}

Keywords Chinese Competitive Sports, Rising Process, National Social Attitudes, Political Appeals

\section{Foreword}

Social attitudes and political appeals, which are firmly connected with social realities in a specific historical stage with profound social and historical roots, are the direct appearance and the subjective reflection of national psychological needs. The rising of nation's Competitive Sports is a long-term process. It only took more than sixty years to accomplish the whole rising process of Chinese Competitive Sports since the year of 1949. We could conclude from the historical trend that there are positive connections among them, which are social attitudes and certain demands of people upon the development and achievements of Competitive Sports.

There are three developing phases of Chinese competitive sports in term of national social attitudes and political appeals in the past sixty years, including the first 30 years (from 1949 to 1978), the latter 30 years (from 1979 to 2008) and the last 7 years (from 2008 to 2015). From the appearance, "gold medal gaining" and "promoting the national prestige" mainly reflected Chinese social attitude and political appeals. From the intensity, it appeared to rise in the first phase in a non-strong way because of international blockade, diplomatic relations break-off and domestic instability. The intensity appeared to fall in the period of Cultural Revolution; the second phase started in 1979 and appeared to rise in a stronger way and came to a climax in Beijing 2008 Olympics due to nationalist sentiment; The third phase started after 2008 and appeared to fall in an obvious way. The thoughts upon the changes of social attitudes and political appeals during the process of the rising of Chinese Competitive Sports would benefit us in the knowing of the past and the future of Chinese Competitive Sports.

1. In the first $\mathbf{3 0}$ years, reluctance to show weakness or suffering disgrace reflected social attitude, while the political appeals were to promote the national prestige, to wash off the shame of "Sick Man of East Asia" and to gain the international dignity in the worldwide playing fields (1949-1978)

\section{1. "Power Complex" and the Realities of Newly-founded China}

We should analysis the social reality of newly founded China before we figure out the social attitude and political appeals since the first 30 years of new China. China is one of the first-class countries with ancient civilization in the world since $19^{\text {th }}$ century. Although "China was invaded and defeated by the western countries" in Opium War, China still has indelible "Power Complex". Chinese got to know western sports and even formed their own understanding of it when they came to contact with the western countries. The 
nationalist sentiment - reluctance to show weakness or suffering disgrace was actually suppressed and not acknowledged by western countries. But on the other hand, "Power Complex" and the idea of "Great China" have never been worn away. Therefore, the nationalist sentiment prospered in every field, including the area of Competitive Sports. At the meantime, the political appeals appeared to promote the national prestige, to wash off the shame of "Sick Man of East Asia" and to gain the international dignity in the worldwide playing fields.

However, there are two aspects we need to deliver. On one hand, China achieved the domestic liberation and independence, and Chinese people became the master of the country with enormous positive energy and had great expectations on the athletes of their performance in the world. But on the other hand, the scope of entries submitted Chinese athletes could participate in was quite small because of domestic instability, international blockade and disconnection with International Olympic Committee (IOC). Although Chinese government endeavored to put themselves in international sports order, in which the western countries took the lead, China were cut off and put on the edge of main stream. In this period of time, the social attitude toward Chinese Competitive Sports was not satisfied, nor the political appeals, which were finitely presented and limited outburst.

\subsection{Reasons of the Social Attitude and Political Appeals with such Characteristics}

"Finitely presented" and "limited outburst" were the main characteristics of this period. On one hand, the newly founded China and socialist system laid a sound foundation for social attitude and political appeals; on the other hand, the domestic changes and the external pressure suppressed the outburst of them.

There are several reasons that the social attitude and political appeals with such characteristics.

i. Newly founded China means a new era with the rising of socialist enthusiasm and nationalist sentiment. In one word, the political independence laid the social foundation and system guarantee for the future of Chinese Competitive Sports.

ii. The label of "Sick Man of East Asia" was the shame of Chinese people, by which they got to know the links and value between the health and modern sports. Western countries thought that Chinese intellectuals were not as good as the Japanese or English, Americans. What caused their opinion was that Chinese were absent from sports. In their eyes, the prosperity of one country was whether the citizens like to be parts of the sports. Interest-Health-Success in sports-Prosperity of a nation was the key words which linked to each other. While Absent from sports-Sick Man of East Asia-Decline of a nation was the descriptions for the Chinese after 100 years of disaster (since 1840). Why did Chinese pay so much attention on the performance in the international playing fields? The answer was that it was not easy to win at that time.

iii. A matter of fact, China never deserved their dignity. They noticed that Competitive Sports was the sign of national prosperity. To win back their dignity became the internal motivation of development of sports. "China had no world record before 1949. And they did badly in final phase of the competition in the Olympic Games. Zero in record was the heavy stone on the heart of every Chinese. ${ }^{,[1]}$ Did Chinese admit their own failure?!

iv. Chinese needed fair communication. The external stimulation became the pressure of Chinese Competitive Sports. "The low-level technique did not match with Chinese international standing, which stimulated Chinese national dignity and outcry for the development of sports." ${ }^{[1]}$

v. The Communist Party and the authority of sports had washing off the shame of "Sick Man of East Asia" as the historical task. Mr. He Long, who worked as the director of National Sports Committee, said that "western countries named us Sick Man of East Asia. We should not allow them to. Who would change the situation? The people who work in sports! The task is difficult but glorious! Sport is a cause of people, which is worth of our try!",[1] "There were only 20 days since the new China was founded; the new leaders already put the development of sports on the urgent agenda." ${ }^{\text {i }}$ On June $20^{\text {th }}, 1952$, Chairman Mao Zedong wrote the inscription for China Sports Federation: "develop sports and strengthen physic health." The inscription not only pointed out the commission and the development direction of sports, but also whistled the participation of the whole society. Taking part in and scoring in international competition and promoting the national prestige are the basic targets of new China's Competitive Sports.

However, the good situation did not last long because of domestic instability, international blockade and cognitive errors. Firstly, the period from 1957 to 1966 happened to be China's Culture Revolution, in which "the high-level political leaders group was unstable. Hence, the politics of China was unstable." ${ }^{[2]}$ All sports undertakings ceased in the period of Culture Revolution. All endeavors, including "Ping-pong Diplomacy" in 1971 and Chinese athletes" outperformance in $7^{\text {th }}$ Olympic Games of 1974, could not save the damage and disaster of Chinese Competitive Sports. China cut off contact with IOC in 1958, which was a huge damage of China and a loss to the development of international sports. Furthermore, "most of the people thought that mass sports activities could not coexist with the improvement of sports skills. The improvement of skills was for the minority, for winning medals and for pure techniques. The thought has affected the work enthusiasm of sports professionals." ${ }^{,[1]}$ The social attitude and political appeals 
upon the Competitive Sports fell to the bottom.

\section{In the Latter $\mathbf{3 0}$ years, The Social Attitudes appeared as the Rising of Nationalist Sentiment, while the Political Appeals were to bring about a Great Rejuvenation of the Chinese Nation with the Olympic Success. (1979-2008)}

\subsection{The Social Attitude Changed from Inferior to Superior, and the Political Appeals Focused on the Gaining of Gold Medals}

30 years after the new China was founded, we washed off the shame of "Sick Man of East Asia". But China still was on the edge of the international sports system, in which the western countries took the lead. The historical task of "achieving a great rejuvenation of the Chinese nation with the Olympic success" was not done yet because of domestic political instability, or the political appeals. Since reform and opening up, the political appeals came about with the rising of nationalist sentiment. There were two aspects for "promoting the national prestige": one is to win more gold medals in the Olympic Games, two is to host the Olympic games in China in order to certify that "Chinese could do the same as the western countries". During the period, the social attitude and political appeals have been changed into efforts to win more medals and to bid for Olympics. They appeared as "fully presented" and "widely outburst".

\subsection{Reasons of the Social Attitude and Political Appeals with Such Characteristics}

"Fully presented" and "widely outburst" were the main characteristics of this period. The domestic stability and unity and the restoration of ICO's seat of China, which brought Chinese back to the international Olympic Games, created conditions for the outburst of social attitudes and political appeals.

There are several reasons that the social attitude and political appeals with such characteristics.

i. Dual effect caused by reform and opening up and the development of economy has changed the social attitude and political appeals. Firstly, ten years of chaos ended, the work of Competitive Sports finally restored due to new changes and new development. The politics was stable, the society was open and steady, and the economy was growing. After ten years' chaos people yearned for peace and success in international playing fields. A new round of "social reform" brought about irreversible development for Chinese Competitive Sports. Secondly, "China's economy began to develop rapidly in 1980" after 30 years' accumulation. ${ }^{[2]}$ In this period, it was not the coincidence that China adopted the "Priority strategy", which also speeded up the development of Chinese Competitive Sports.

ii. The international changes brought Chinese Competitive Sports new opportunities and challenges. Firstly, ICO gave back the seat to China, which ended 20 years' international isolation and blockade and provided an important platform for the development of Chinese sports. Secondly, the sports techniques of China lag far behind U.S.A., the Soviet Union, Germany, Japan, and etc.. Thirdly, the governments of the Soviet Union and the whole Europe wobbled since the eighties of $20^{\text {th }}$ century. Competitive Sports in these countries has been damaged since then, which offered China the best opportunity of development, so-called "strategical opportunity stage".

iii. The sports professionals put hard work and effort into the development of Competitive Sports. Firstly, the first 30 years of unstable politics and left-wing political thought caused the loss of development opportunity. Since reform and opening up, Chinese people cherished the new opportunity. Secondly, the sports professionals were full of enthusiasm toward the development of sports. Thirdly, all Chinese were aware of "the situation that we lag far behind in the field of sports, and were eager to get rid of the bad situation." "감 $F$ ourthly, "the thought of surpassing" the western countries appeared to rise. "The effect between China and western countries is mutual, but the nature and the extent of effect are different." ${ }^{[3]}$ Fifthly, the awareness of gold medal appeared to rise. Competitive Sports seemed to not as important in a closed-off country as in an opening-up one. "As soon as the country melt into the outside world, all the information about Competitive Sports would flow into and caused the awareness of gold medal." [3]

iv. Competitive Sports began to rise in the strategy of "strong in sports". The government put forward a slogan: "break Asia records and set sight on world level" in sports in early $80^{\text {th }}, 20^{\text {th }}$ century and also set up an aim which built "a strong nation in sports" by the end of $20^{\text {th }}$ century. Firstly, National Sports Development Strategy Seminar proposed the thought of "achieving take-off the sports undertakings with revolution as base and with socialization \& scientification as the wings" in 1985 . The indicators of Competitive Sports of the thought are the indicators of achieving the goal of strong in sports of the nation. The seminar proposed the strategy of "public-involved sports with the teenagers as the emphasis and with the Olympic games as the ultimate aim". "Program of Striving for Olympic Glory" (Priority Rising) was finally put forward after 
several meetings hosted by State Sports Committee. Secondly, Competitive Spots faced not only "the opportunity of Strategic Development", but also many realistic problems: how to achieve the goal of strong in sports of the nation in the primary stage of socialism and what model of development to choose. The strategy of Priority Rising reflected the public social attitudes and political appeals, which highlighted the advantages of "public-involved Competitive Sports" and the sacrifices made for the development of it.

v. Chinese government made many measures under "the strategy of strong in sports" and "public-involved" advantages. Firstly, the sports resources should be fully utilized. The sports professionals found out that plateau environment, such as Yunnan province, Guizhou province and Qinghai-Xizang Plateau, was important to the training of aerobic endurance events. South China is good for the training of swimming and other water sports, while North China is good for winter sports." China is a socialism country with a great amount of sports resources. The government allows various forms and flexible ways to select intellectuals in sports market. And the government could support unconditionally the development of sports professionals and key researches." ${ }^{[4]} \mathrm{We}$ could use the advantages of ethnic heritage and culture in some programs. "In order to improve the level of the athletes' skills, the State Sports Committee concentrated the human resources, materials resources and fund to develop dominant events and some programs which could be finished in short term under the strategy of stressing the key point.. ${ }^{[4]}$ In 1989, the government set up an overall arrangement on 18 key programs in term of sports professionals, and built sports training bases directly subordinated to State Sports Committee, which formed the sports technological network of S.S.C.. Secondly, the government adopted "strategy shift" on Summer Olympics, "which continued focusing on the ball games and put the games of track \& field events and swimming on priority." [5]

vi. Social attention and public enthusiasm. From "participation" in 80 's to "bid" in 90's and to "host" in 2008, Chinese people's enthusiasm has been last for almost 30 years. Firstly, "sports heat" appeared in early 80 's of $20^{\text {th }}$ century. Since China's seating was restored in I.O.C., the sports professionals proposed the slogan of "break Asia record, set sight on world level in sports" and "promote the prestige of China". At the very first, China's male volleyball team played with the Korean team in Asian Volleyball Game and converted defeat into victory, which was highly praised by the whole China. Many college students in Beijing crowded into the streets and celebrated the success with the slogan of "unite together and revitalize the Chinese nation". Right after that, China's female volleyball team achieved five successive championships in the whole world. Mr. Zhu Jianhua broke the world record of male high jump for two times in 1983. China sports delegation took part in the $23^{\text {rd }}$ Olympic Games and broke the "zero" record in gold medal-gaining in 1984, which pushed the "sports heat" to the climax. It was the common reflect of social and political enthusiasm. It was also the sentimental outburst from the shame of "Sick Man of East Asia" to "real Chinese". Mr. Zhu Zhenwu thought that "the spiritual core and internal impetus is the wish of revitalizing Chinese nation". ${ }^{[6]}$

Secondly, another climax of Olympic heat came. Since reform and opening up, the economy of our country has developed, the politics and the society have been stable, the people's livelihood has been improved, and the sports undertakings have been achieved successfully with the host of Beijing Asian Games, all of which boosted bigger desires. On Feb $2^{\text {nd }}, 1991$, Beijing government submitted the application for hosting the Olympics in 2000, and the Chinese government backed up the decision of Beijing government on Mar $9^{\text {th }}$. Although the application failed, the bid in 2008 was a big success, which showed that Chinese and its politics made "the century's wish come true".

\section{Since the Beijing Olympics, the national social attitude diversified while the Gold Medal became not as important as before. And the political appeals were the pursuit of "Harmonious World". (2009 till now)}

\subsection{The Historical Task of "The Great Rejuvenation of the Chinese Nation" Has Been Accomplished, and the Gold Medal was devalued}

China ranked top one in gold medal-gaining in 2008 Beijing Olympics, which was unprecedented in history and the political appeals were fully achieved ever since China was founded. The success of Beijing Olympics satisfied the social attitude of the whole nation, from which the historical task and contribution of Competitive Sports have accomplished "the great rejuvenation of the Chinese nation". Meanwhile, this success became the milestone and the turning point of the history of Chinese Competitive Sports. Since then, gold medal became less important. The social attitude and political appeals became stronger since China ranked top 2 in gold medal-gaining in 2012 Olympics, which appeared as "moderately presented" and "modestly erupted".

\subsection{Reasons of the Social Attitude and Political Appeals with such Characteristics}

"Moderately presented" and "modestly erupted" were the 
main characteristics of this period. On one hand, China hosted the 2008 Olympic Games, which satisfied the Chinese national dignity; on the other hand, the fast development of China's economy and society, which lead to diversified social value, resulted in Competitive Sports less important than before.

There are several reasons as following:

i. China's society has been diversified with social attitude. It underwent from "popular democracy", "conflict philosophy" and "construction philosophy" to "harmonious philosophy" ${ }^{[7]}$. The priority of the stage of "harmonious philosophy" is to build a harmonious society and push to build a harmonious Asia and a harmonious world. In this stage, the social attitude and political appeals have changed, which leaded to the changes of people's understandings upon sports \& politics and gold medal \& politics. The political meaning of gold medal became less important than the value of human beings themselves. The new political appeals upon sports were the pursuit of "Harmonious World".

ii. National self-esteem has been satisfied in a certain extent. On one hand, the success of Beijing Olympics brought China from "the edge of world civilization" back to "the center of world civilization". On the other hand, there was no novelty (Olympics besides), for which Chinese people would want to seek. There was nothing the western countries could not share with us. In the meanwhile, the achievements on economy brought China toward the center of world, which was faster than Chinese people expected. Compared to the year of 1979 and 1949, the social attitude and political appeals were satisfied and the national self-esteem has been reinforced and became more reasonable.

iii. The sports professionals began to discuss the transformation of Chinese sports' development. They took Tokyo Olympics toward Japan's development of Competitive Sports as the example and predicted the future of ours after 2008 Beijing Olympics. Relative researches have been done, which made people believe to see the future of Chinese Competitive Sports.

iv. The government has been thinking the advantages and disadvantages of China's sports system. "public-involved system" did make great contribution to the success of China's sports system. But it also showed the shortcomings with the development of society. Extensive strategy of huge-crowd, the contradiction between management and training and the retirement \& placement of athletes are huge obstacles of sports' development. How to transform the development pattern of China's sports is the realistic subject.

v. The importance of Competitive Sports in China's politics became significantly decreased. Firstly, State
Sports Committee degraded to Administration of Sports of China, which triggered the changes. Secondly, China didn't have to show strength by Competitive Sports as it did before reform and opening up. China is the second biggest entity after the United States in the world. The sense of urgency to become the biggest country in the world has faded, although there are still plenty of political appeals in today's China. China has passed the time in which it depended on Competitive Sports to maximize national interest in the world.

\section{Conclusions}

The rising of China's Competitive Sports has been affected by the social attitude and political appeals. The stronger the social attitude and political appeals are, the faster the development of Competitive Sports goes. After China achieved "the great rejuvenation of Chinese nation" by "promoting the national prestige" with the success of Olympics in 2008, the public attention upon the gold medal decreased and continued decreasing. Meanwhile, "Harmonious world" became the new political explore and appeals when the changes of diversified society and political condition brought about the faded attitude upon the gold medal. Today, when we retrospect the development of China's Competitive Sports, we have to acknowledge that its great achievements have been absolutely affected by the social attitude and political appeals. This is the historical logic and sure event of China's Competitive Sports.

\section{REFERENCES}

[1] Shaozu W. Sport's history of P.R.C. [M] Beijing: Chinese Book Company. 1999:8, 13,11,12,13. Chinese

[2] Angang H. How to view the trend and challenge of our economic society [J]. China opening herald. 2005, (5): 33, 32. Chinese

[3] Zhengming Z. Ten problems need to be solved on the way of strong country in sports [J]. Journal of Harbin institute of P. E. 1989, (3): 7,8,9. Chinese

[4] Xianming S. Review on several problems of our sports development strategies \& reasonable utilization of sports resources [J]. Journal of Wuhan institute of P.E. 1992, (1): 16, 17. Chinese

[5] Yujie P. Strategy Shift on summer Olympics [J]. Journal of Harbin institute of P. E. 1986, (1): 6. Chinese

[6] Zhenwu Z. Analysis on sports heat in the past 40 years and predictions on the future [J]. Sports history. 1989, (6): 9. Chinese

[7] Angang H. China road (1949-2009) (second volume) [J]. Management on farm economy. 2011, (3): 15-16. Chinese 